Research Article

\title{
Design of Negative Pressure Spiral Feeding Device for Tangential and Longitudinal Axial Intersection of Combine Harvester
}

\author{
Zhong Tang $(\mathbb{D}$, Xiyao Li, Xinda Chen, and Yang Chen \\ School of Agricultural Equipment Engineering, Jiangsu University, Zhenjiang 212013, Jiangsu, China \\ Correspondence should be addressed to Zhong Tang; tangzhong2012@126.com
}

Received 19 January 2019; Revised 4 April 2019; Accepted 25 May 2019; Published 10 June 2019

Academic Editor: Guoqiang Xie

Copyright (C) 2019 Zhong Tang et al. This is an open access article distributed under the Creative Commons Attribution License, which permits unrestricted use, distribution, and reproduction in any medium, provided the original work is properly cited.

\begin{abstract}
A difficult problem occurred with straw clogging at the tangential and longitudinal axial intersection of rice combine harvesters, which seriously affected the efficiency and reliability of the threshing cylinder. The primary objective of this paper was to design a negative pressure spiral feeding device by CFD (computational fluid dynamics). The negative pressure spiral feeding combined structure of the tangential threshing cylinder and longitudinal axial threshing cylinder was established by Pro/E software. Then, the flow path model of the negative pressure spiral feeding device was analyzed by CFD. The airflow velocity distribution of the spiral feed head semicircular cross section and power consumption of the longitudinal axial spiral feeding head were used to verify the effectiveness and rationality of the negative pressure spiral feeding device. The results showed that the two-blade spiral structure and $30 \mathrm{~mm}$ pitch shroud structure were more suitable to ensure the smooth flow of straw at the tangential and longitudinal axial intersection. The resistance of the feeding head would cause the power consumption curve fluctuation. The power consumption curve of the improved shroud spiral feed structure was a stable regular fold line without upward trend. When the power consumption curve has an always upward trend, it means that congestion is about to happen. The characteristics of the power consumption curve indicated that the shroud negative pressure spiral feed device designed in this paper was reasonable and effective.
\end{abstract}

\section{Introduction}

At present, with the increasing of rice yield, the threshing device for rice harvesting has also been changing. The tangential threshing cylinder and longitudinal axial threshing cylinder were the two main degranulation structures. Three types of threshing device have reached common use in recent years of innovation and development of combine harvesters. The first type was a single or multiple tangential threshing cylinders. The second type was a single or multiple longitudinal axial threshing cylinders. The third type was the combined structure of tangential threshing cylinder and longitudinal axial threshing cylinder. The combined single tangential and longitudinal axial threshing cylinders were proven to be suitable for Asian small and medium combine harvester [1]. However, there was a straw clogging problem at the tangential and longitudinal axial intersection. When rice straw trajectory changed from tangential motion to longitudinal axial motion, the feeding congestion often occurred. Poor feeding of rice straw seriously affected the working efficiency and reliability of the threshing cylinder.

When the threshing cylinder performed grain threshing, the power consumption curve of the cylinder was an important characterization of the running status of the threshing cylinder [2]. The threshing power consumption during the threshing process was tested and analyzed by $\mathrm{Lu}$ [3] and Srison et al. [4]. Damping and power consumption characteristics during the threshing process were obtained. Mazara et al. indicated that isometric steady-state was affected by an eccentric contraction impairing torque steadiness [5]. Michele et al. also compared evaluation of insertion torque and mechanical stability for self-tapping 
and self-drilling spiral device [6]. When the spiral feeding device was clogging, the power consumption curve of the barrel sharply increased. Changes in the power consumption curve were also often used to be an important sign to determine whether the barrel was clogging. So, the power curve of threshing cylinder could be used to evaluate the smoothness of the threshing cylinder feeding.

As is well known, the efficiency of threshing cylinder directly affects the performance of the whole combine harvester. There were many researches on the threshing ability of cylinder, the reduction of threshed grain loss, and the structure optimization of the threshing cylinder. Li et al. designed a split combination header with integrated cutting, conveying, re-cutting, and gap adaptive adjustment function due to the entanglement or clogging phenomenon [7]. It can automatically adjust the gap between the conveyor and the header floor in real time to improve the adaptability of the unit to fluctuations in feed volume. Wei et al. tested the parameters of the conical spiral feeding device and indicated that the feeding capacity of the spiral feeding structure determined the threshing efficiency of cylinder [8]. Qu et al. tested the spiral feeding head feeding capacity of the longitudinal axial threshing cylinder at different feeding rates [9]. The matching relationship between different feeding rate and the optimal rotation speed of the threshing cylinder was obtained. Su et al. studied on the corn threshing and feeding ability of longitudinal axial threshing cylinder at different moisture contents [10]. These results showed that because the corn ear was small and independent, the ability of the vertical feeding head to grasp the corn was closely related to the longitudinal axial cylinder speed and feed rate. It can be seen that the spiral feeding device determined the threshing ability of longitudinal axial threshing cylinder. The straw clogging problem at the tangential and longitudinal axial intersection was an urgent problem to be solved.

Based on the principle of axial flow pump, the airflow generated by the high-speed rotation of the spiral blade can be used to assist the feeding ability, thereby improving the smoothness of the material at the feeding inlet. The volute structure shape and impeller shape had a great influence on the performance of axial flow pump. The placement of the blades had a large influence on the saddle area of the axial flow pump. The energy characteristics and pressure pulsation characteristics of axial flow pump in the saddle area were analyzed by $\mathrm{Wu}$ et al. [11]. The running characteristics of axial flow pump saddle area near the blade placement angle were obtained. He et al. analyzed the running characteristics of the axial flow pump [12]. It can be seen that when the spiral feeding head of longitudinal axial threshing cylinder was being designed, it was necessary to consider the structure of the spiral feeding vane. At the same time, it was also necessary to consider the structural parameters of the axial flow outer casing matched with the spiral feed head [13]. There were spiral blades on the feed head of the longitudinal axial threshing cylinder. By comparing the axial flow pump with the axial spiral feeding device [14], the tangential and longitudinal axial intersection was similar to the axial pump saddle area. The saddle area design idea of axial flow pump can be used to design a negative pressure spiral feeding device by CFD to solve the clogging problem occurring at the junction of the tangential and longitudinal axial intersection.

In 2011, Mao et al. regarded the grain in the threshing space as a fluid medium. The mathematical model for the motion state of the grain flow was established [15]. The mathematical model of rice stalk movement state was established and analyzed. The fluent fluid numerical simulation was used to analyze the movement of the stems at the threshing teeth. The correctness of the ANSYS fluent numerical simulation data was verified by high-speed photography. For the blockage problem of the tangential and longitudinal axial intersection, this paper designed a negative pressure spiral feeding device by the principle of CFD. The flow path model of the negative pressure spiral feeding device was established by Pro/E and analyzed by using CFD. The airflow velocity distribution of spiral feed head semicircular cross section and power consumption of longitudinal axial spiral feeding head were used to verify the effectiveness and rationality of negative pressure spiral feeding device.

\section{Materials and Methods}

2.1. Spiral Feeding Device. Rice straw was sent to the tangential threshing cylinder to be threshed and separated originally and then entered into longitudinal axial threshing cylinder to be re-threshed and re-separated [16]. When straw trajectory changed from tangential motion to axial motion, straw clogging problem would happen at the tangential and longitudinal axial intersection. The combined device of the tangential and longitudinal axial threshing cylinder intersection is shown in Figure 1(a).

There were three parts of spiral feeding device. The upper and lower portions of the spiral feeding device were a threshing cylinder cover and a gravure screen, respectively. The diameter of longitudinal axial threshing cylinder was $540 \mathrm{~mm}$, and its total length was $1660 \mathrm{~mm}$. There were helical blades $270 \mathrm{~mm}$ in length in front of the longitudinal axial threshing cylinder. The straw diversion cap on the threshing cylinder is shown in Figure 1(b). The longitudinal axial threshing cylinder is shown in Figure 1(c). Grid gravure screen under the threshing cylinder is shown in Figure 1(d).

As shown in Figure 1, the straw diversion cap was installed on top of longitudinal axial threshing cylinder. Grid gravure screen was installed under the longitudinal axial threshing cylinder. Then the longitudinal axial threshing cylinder was located in the space formed by grid gravure screen and straw diversion cap. There was a gap of $30 \sim 50 \mathrm{~cm}$ around the longitudinal axial threshing cylinder.

2.2. Axial Flow Spiral Conveying Mode. Based on the design theory of computational fluid dynamics, the feeding head of the longitudinal axial threshing cylinder was designed as an axial flow spiral conveying mode $[17,18]$. By designing the outer shroud of the spiral vane, the rotating axial vane produced a negative pressure conveying function. Axial negative pressure spiral feeding device is shown in Figure 2(a). In order to make axial negative pressure spiral feed device connected to 


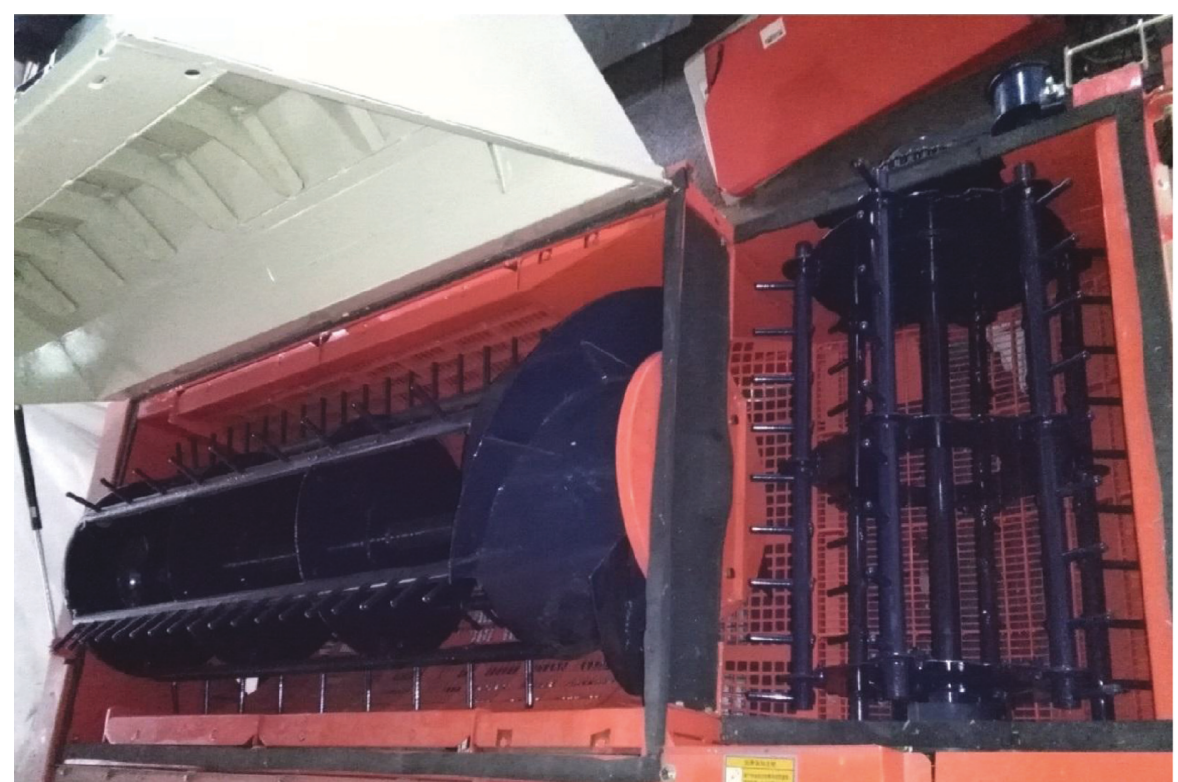

(a)

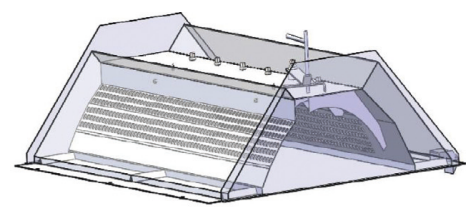

(b)

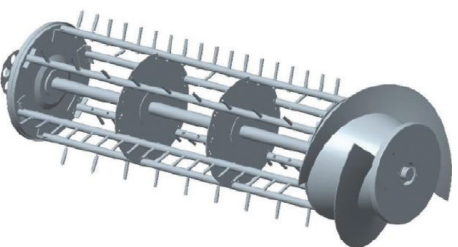

(c)

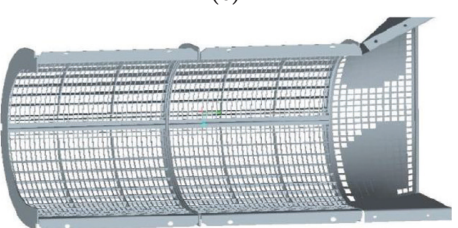

(d)

FIgure 1: Composition and components of the longitudinal axial threshing device. (a) Tangential and longitudinal axial intersection picture. (b) Straw diversion cap. (c) Axial threshing cylinder. (d) Grid gravure screen.

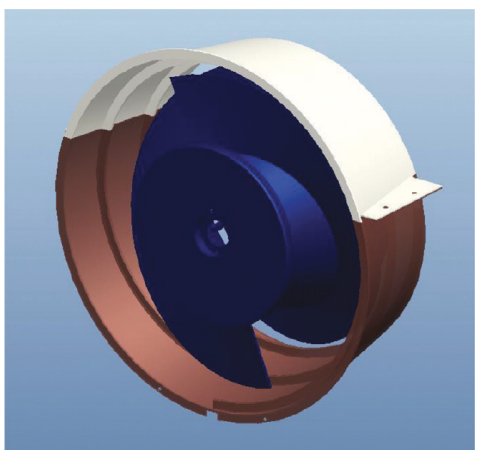

(a)

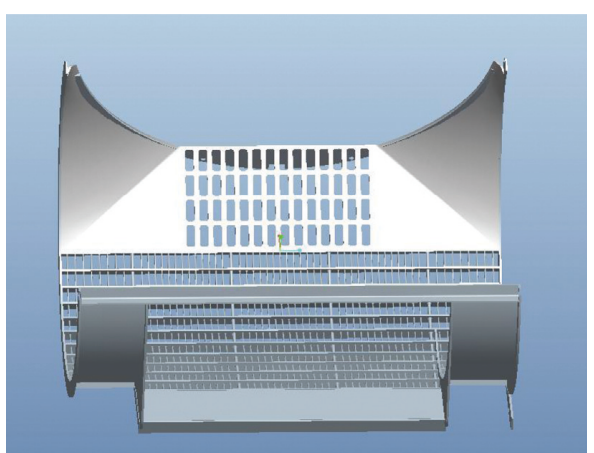

(b)

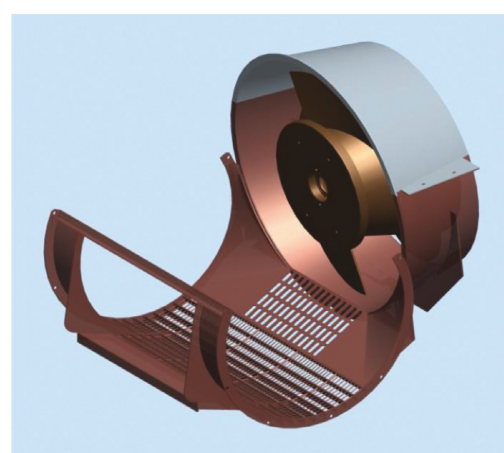

(c)

Figure 2: Axial negative pressure spiral feeding structure and assembly. (a) Axial negative pressure spiral feed device. (b) Tangential threshing cylinder grid gravure screen. (c) Negative pressure spiral feeding device assembly.

cylinder grid gravure screen of tangential threshing cylinder, which could form a smooth airflow path model, the tangential threshing cylinder grid gravure screen was designed and is shown in Figure 2(b). Then, the negative pressure spiral feeding device assembly is shown in Figure 2(c).

The 3D model of negative pressure spiral feeding combined structure of transversely tangential threshing cylinder and longitudinal axial threshing cylinder was established by Pro/E software [19]. The movement of rice stems in the threshing device was very complicated. In order to execute the CFD numerical simulation (ANSYS Fluent 6.3.26), it was necessary to rationally simplify the structure in the rice threshing device. In the CFD numerical simulation, the geometric model was the flow path model of fluid. It was a physical place where there was fluid. The area where no fluid passed was required to be hollowed out, i.e., the physical features of the part were removed. The rice threshing device was divided into three zones, namely, tangential axial threshing cylinder zone, longitudinal axial threshing cylinder zone, and tangential and longitudinal axial intersection.

The mesh quality of the model directly determined the accuracy of numerical simulation. Based on the complexity of flow field in rice threshing device, a tetrahedral unstructured grid was used in this paper. Meshing was performed on the computational domains of the three independent regions. Flow path model of the negative pressure spiral feeding device was established by using CFD (computational fluid dynamics) [20]. The computational domain of the tangential threshing cylinder, longitudinal axial threshing cylinder, and negative pressure spiral feeding device was meshed. Results generated an "uns" grid file. Finally, the assembly model grid was merged and generated an overall grid in each individual computational domain grid. Mesh model of the axial spiral feeding device is shown in Figure 3(a). 


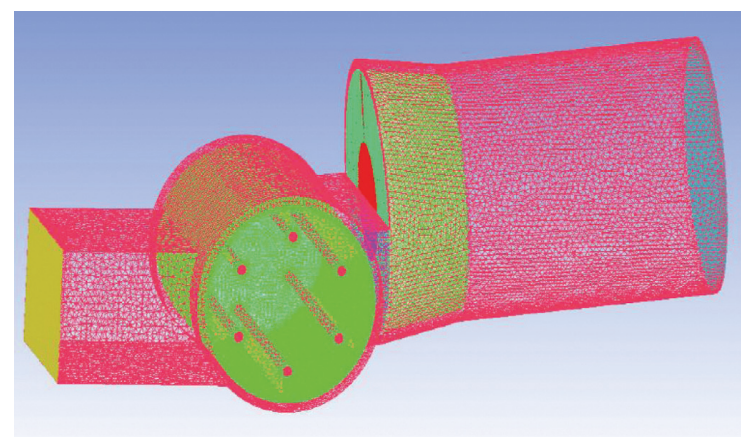

(a)

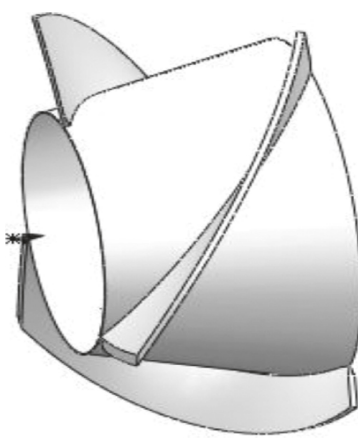

(b)

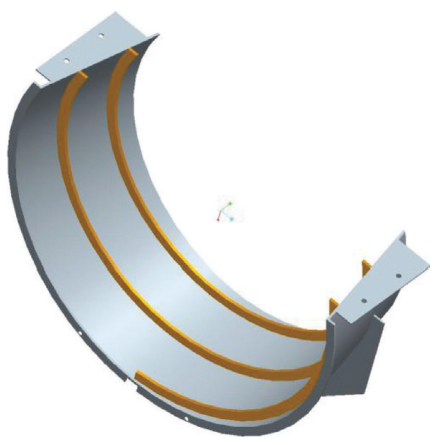

(c)

FiguRE 3: Axial flow spiral conveying mode of the negative pressure spiral feeding device. (a) Mesh model of the axial spiral feeding device. (b) Blade spiral. (c) Shroud pitch.

According to rice threshing principle, the structure and size of longitudinal axial threshing device were difficult to change. Then two important variables of longitudinal axial flow spiral conveying mode were blades spiral and shroud pitch. In this paper, two-blade spiral and three-blade spiral headed ones were used to analyze the characteristics of negative pressure. The spiral feeding blade of three-blade spiral is shown in Figure 3(b). In order to analyze the diversion effect of the $30 \mathrm{~mm}, 40 \mathrm{~mm}$, and $50 \mathrm{~mm}$ radial pitch, the structure of the shroud with different radial pitches is shown in Figure 3(c).

2.3. CFD Calculation Model and Solution Method. Since the axial airflow generated by the longitudinal axial threshing cylinder was similar to that of an axial flow pump, the flow field inside the longitudinal axial threshing device was considered to be a turbulent viscous model. The internal flow field differential governing equation followed the law of conservation of mass and the law of conservation of momentum. At the same time, the differential governing equation satisfied the viscous fluid motion equation and the continuity equation. Therefore, when solving the flow field inside the longitudinal axial threshing device, the following assumptions can be made for the internal flow field:

(1) Regardless of the change in airflow density, it was assumed that the airflow inside the longitudinal axial threshing device was an incompressible gas

(2) Assuming that there was no heat exchange in the flow process inside the longitudinal axial threshing device, the energy conservation equation was not considered

(3) The tangential and longitudinal axial intersection areas were assumed to be confined spaces

In industrial flow computing [21], the $k-\varepsilon$ model was currently the most widely used model. It mainly consisted of three forms, standard $k-\varepsilon$ models, RNG $k-\varepsilon$ models, and realizable $k-\varepsilon$ models. The standard $k-\varepsilon$ model was not ideal for complex flow simulations with large curvature and strong pressure gradients. The realizable $k-\varepsilon$ model was a variant of the standard $k-\varepsilon$ model, which used mathematical constraints to improve model performance. Compared to the standard $k-\varepsilon$ model, the realizable $\mathrm{k}-\varepsilon$ model was a good predictor of moderate-intensity swirl. The realizable $k-\varepsilon$ turbulence model in the calculation was used in this paper.

There were two types of solutions in fluent, which were pressure-based solver and density-based solver. The pressurebased solver's momentum equations were solved sequentially. Pressure-based solvers were commonly used in low-speed uncompressible flows. The mass equation, momentum equation, energy equation, and composition equation of the density-based solver were solved by coupling. The densitybased solver needed to perform multiple iterations before getting a convergent solution. Density-based solvers were commonly used in high-speed compressible flows. The pressure-based solver was used in this paper.

Before the numerical simulation calculation, the corresponding boundary conditions of the model needed to be set. The reasonableness of the boundary condition setting would directly affect the calculation accuracy and computational convergence of the simulation results. This paper set the working pressure to one atmosphere $(101.325 \mathrm{~Pa})$. The pressure value obtained by the simulation was with respect to atmospheric pressure. Fluent had many types of boundary conditions, such as mass flow inlet, pressure inlet, and velocity inlet. Pressure values and pressure distributions at the entrance of tangential and longitudinal axial intersection areas were not easily measured. However, the airflow velocity at the entrance of the tangential and longitudinal axial intersection areas could be easily measured. Therefore, the model entry used velocity inlet. The direction of airflow velocity was perpendicular to the entrance plane of the tangential and longitudinal axial intersection areas.

The tangential and longitudinal axial intersection areas were the pressure outlet. The pressure was set to $0 \mathrm{~Pa}$. Rotating wall conditions and MRF models were used in the tangential and longitudinal axial intersection. The rotational speed of the rotating wall was relative to the velocity of surrounding fluid. In CFD simulation, the rotating speed of the tangential threshing cylinder was $726 \mathrm{r} / \mathrm{min}$ and the rotating speed of the longitudinal axial threshing cylinder was $629 \mathrm{r} / \mathrm{min}$. 
2.4. Processing and Testing of Spiral Feeding Device. In order to test the rationality of the design and processing assembly of the negative pressure spiral feeding device, it was necessary to measure and analyze the airflow velocity at the inlet of the spiral feeding device. Using AVM-05 airflow speed tester manufactured by Taiyi Electronics Co., Ltd, the airflow velocity at spiral blade feed inlet was measured. The airflow velocity measurement range was $0-45 \mathrm{~m} / \mathrm{s}$. The sensitivity was $0.5 \mathrm{~m} / \mathrm{s}$. And, the error was $3 \pm 0.3 \%$. The maximum value of the airflow in each direction measured by the AVM05 type airflow speed tester was used as a result. The top view of assembly results is shown in Figure 4(a). The inlet airflow test scenario is shown in Figure 4(b).

As shown in Figure 4(a), the spiral feed head and the outer shroud in the red square formed an axial flow pump. The air inlet at the spiral feed head had a semicircular cross section. The inner side of the shroud had a large diameter of $780 \mathrm{~mm}$ and a tapered feed head with a diameter of $400 \mathrm{~mm}$. Divide the air inlet into $3 \times 7$ wind speed measuring points. From the center of the circle, the three sets of circumferences were defined as 1 layer (the upper layer), 2 layer (the middle layer), and 3 layer (the lower layer). Each layer of half circumferences was equally divided into 7 measurement points. Measuring point distribution is shown in Figure 4(c). Because the airflow velocity fluctuated, the average was taken three times for each test. In this paper, Origin 9.0 software was used to plot the wind speed distribution polar coordinate cloud of the inlet section. The polar contour theta $(X) r(Y)$ method was used, where $Y$ is the polar coordinate position and $X$ is the angle.

\subsection{Longitudinal Axial Threshing Cylinder Feeding Power.} When the longitudinal axial threshing cylinder was threshing rice, the rice straw was always attached to the threshing cylinder rods [22]. Rice threshing process and straw attached to the longitudinal axial threshing cylinder are shown in Figure 5(a). The power status of the threshing cylinder had been investigated many years ago [23]. Threshing shaft torque during threshing process was studied by many researchers [24]. The power curve of the threshing cylinder could be used to evaluate the smoothness of the threshing cylinder feeding [2,25]. The patch was placed on the sprocket of the end face of the longitudinal axial threshing cylinder. The torque and rotational speed of the drive shaft were used in the strain gauge principle. In order to develop the dynamic load test system of drive shaft, gage patch (BE120-4AA(11)) resistance strain gauges $(119.9 \pm 0.1)$ $\Omega$ and MF-G14 silicone and hall speed sensor (CHE1815N11-HZF710) were used to test the torque and speed signals of drive shaft. In this dynamic load test system, DH$5905 \mathrm{Wi}-\mathrm{Fi}$ wireless test technology was shown in some studies [26]. The resistance strain gauge load test system of the longitudinal axial threshing cylinder is shown in Figure 5(b). All the torque and speed signals were collected by the DH-5905 wireless acquisition system. The torque and speed signals were sent to a laptop by a wireless card.

The torque factor $T$ and the output voltage value $\mathrm{U}$ in the calibration data were determined by the least squares method:

$$
a=\frac{\sum_{i=1}^{k}\left(T_{i}-\bar{T}\right)\left(U_{i}-\bar{U}\right)}{\sum_{i=1}^{k}\left(T_{i}-\bar{T}\right)^{2}},
$$

where $T_{i}$ is the calibrated torque value, $\mathrm{N} \cdot \mathrm{m} ; U_{\mathrm{i}}$ is the output voltage value corresponding to the torque value, $\mathrm{mV} ; \bar{T}$ is the arithmetic mean of the calibrated torque, $\mathrm{Nm} ; \bar{U}$ is the average value of the output voltage, $\mathrm{mV}$; and $a$ is the scale factor, $\mathrm{mV} /(\mathrm{N} \cdot \mathrm{m})$.

The proportionality coefficient $a$ of the longitudinal axial threshing cylinder shaft was obtained by processing the static calibration data, which was $0.00224 \mathrm{mV} /(\mathrm{N} \cdot \mathrm{m})$. Based on the calibration curve of the longitudinal axial threshing cylinder shaft torque sensor, its calibration curve equation was $Y=0.0012243 X+0.003428$. The range was from 0.9962 to 0.9999 , and the reliability of the trend line could be considered to be suitable.

The types of speed sensors mainly included variable reluctance type speed sensor, photoelectric speed sensor, Hall speed sensor, and capacitive speed sensor. In order to ensure the installation accuracy and test accuracy of the speed sensor and make the bracket light, this paper selected the Hall speed sensor and fixed it on the bracket. The bracket was welded on the outer end frame of the corresponding shaft. The mounting position of the Hall sensor at the outer end of the intermediate shaft is shown in Figure 5(b). The power consumption $P$ was calculated by calibrated torque value and rotational speed of drive shaft:

$$
P=\frac{T n}{9550},
$$

where $P$ is the power consumption of the threshing cylinder; $T$ is the torque value of threshing cylinder; and $n$ is the rotational speed of the drive shaft.

In order to test the power curve of the longitudinal axial threshing cylinder, a combine harvester of CFFL850 crawler combine harvester (manufactured by Chinese Changfa Fengling Agricultural Machinery Co., Ltd.) was taken as the experimental prototype. The power curves of longitudinal axial threshing cylinder were tested at forward speed of $0.98 \mathrm{~m} / \mathrm{s}$ with straw stubble height of $20 \mathrm{~cm}$. The rice sample (Oryza sativa L. rice cultivar "zhendao10") was grown in Danyang of Jiangsu Province, China. The average moisture contents of stalks and grain was $68 \pm 3 \%$ and $24 \pm 0.5 \%$, respectively. Two types of power consumption curves were tested and analyzed under the same feeding conditions of $7 \mathrm{~kg} / \mathrm{s}$. The complete parameter estimation procedure and results of all sample tests were repeated five times to reduce the impact of random influence on choice of the training and validation sets. The average results were compared by least significant difference (LSD) post hoc test at the $5 \%$ significance level $(p<0.05)$.

\section{Results and Discussion}

3.1. Different Headed Blade. Airflow simulation was performed on the structure of the two-blade spiral and the threeblade spiral. The maximum radial spacing between the spiral vanes and the shroud was set to $40 \mathrm{~mm}$. The center profile of 


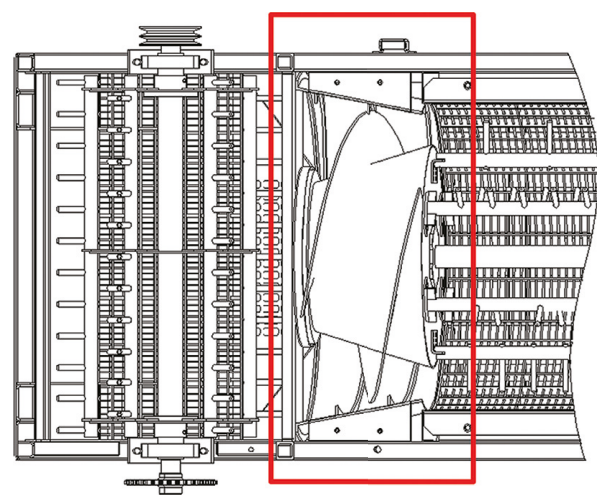

(a)

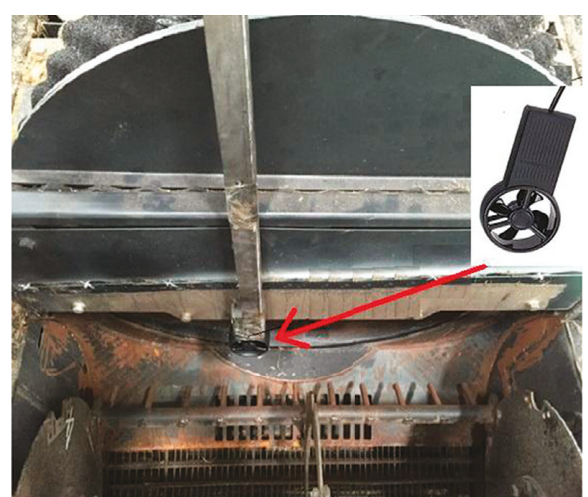

(b)

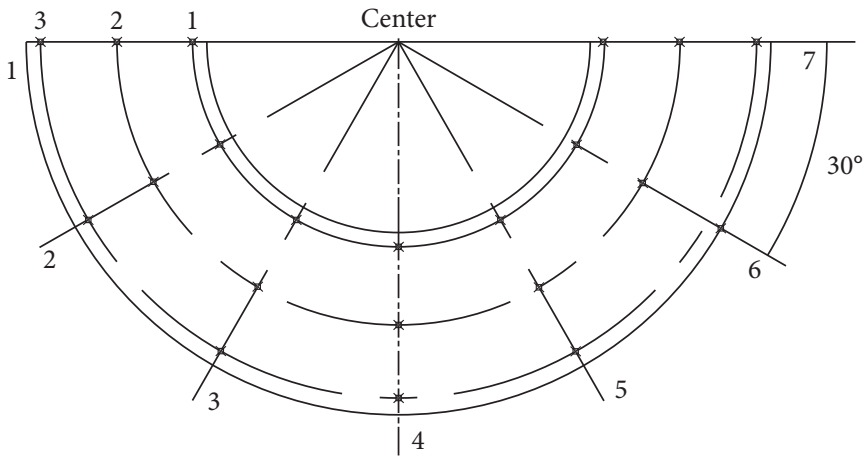

(c)

Figure 4: Performance testing of the negative pressure spiral feeding device. (a) Top view of assembly results. (b) Inlet airflow test with AVM-05 tester. (c) Measuring point distribution.

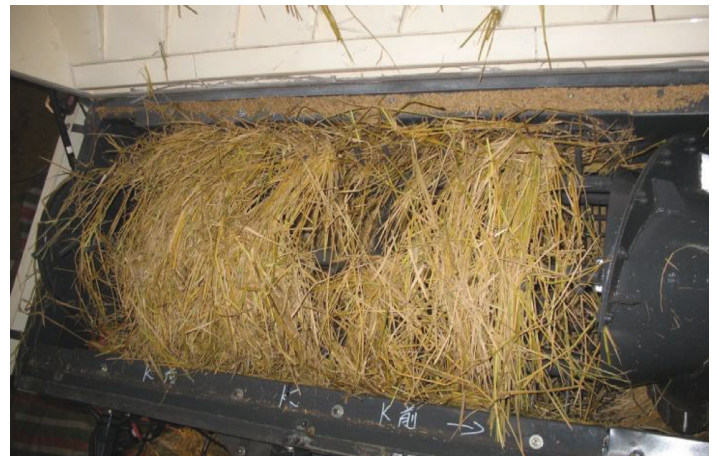

(a)

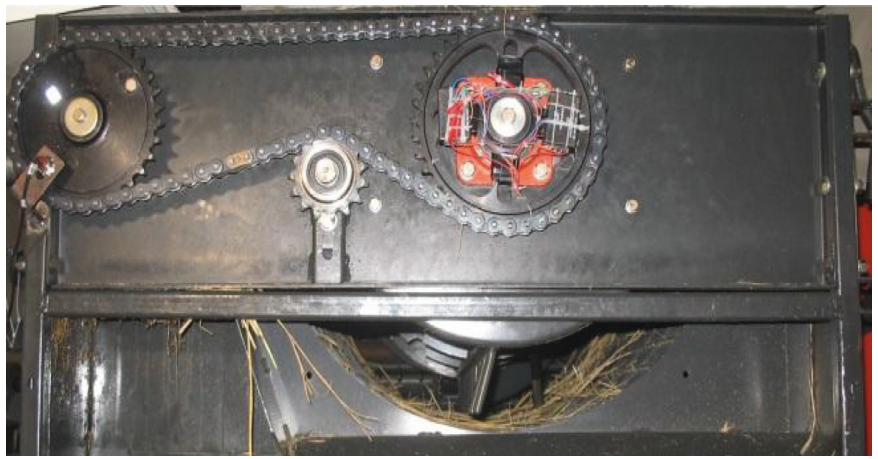

(b)

Figure 5: Drive shaft dynamic load test of the rice threshing process. (a) Rice longitudinal axial threshing process. (b) Resistance strain gauge load test.

the spiral feed device was selected for airflow field analysis. The airflow characteristics of the two-blade spiral simulation are shown in Figure 6(a). The airflow characteristics of the three-blade spiral simulation are shown in Figure 6(b).

As shown in Figure 6(a), the airflow field of the two- and three-blade spiral structure flowed smoothly. The maximum airflow rate was concentrated in the flow path area of the spiral feed system area. The airflow velocity at the air inlet of the two-blade spiral structure was $6.59 \mathrm{~m} / \mathrm{s}$ to $11.5 \mathrm{~m} / \mathrm{s}$. The airflow velocity at the tangential and longitudinal axial intersection was $3.34 \mathrm{~m} / \mathrm{s}$ to $9.85 \mathrm{~m} / \mathrm{s}$. As shown in Figure 6(b), the airflow had a reflow phenomenon at the tangential and longitudinal axial intersection. The air velocity at the air inlet of the three-blade spiral structure was $7.78 \mathrm{~m} / \mathrm{s}$ to $13.6 \mathrm{~m} / \mathrm{s}$, which was greater than the airflow velocity at the air inlet of the two-blade spiral structure. However, the internal airflow reflow phenomenon of the three-blade spiral structure was more serious than the interior of the two-blade spiral structure. The three-blade spiral structure had a gas velocity of $3.34 \mathrm{~m} / \mathrm{s}$ to $9.85 \mathrm{~m} / \mathrm{s}$ at the tangential and longitudinal axial intersection, but it was smaller than the two-blade spiral structure. 


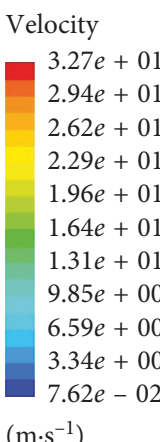

$\left(\mathrm{m} \cdot \mathrm{s}^{-1}\right)$

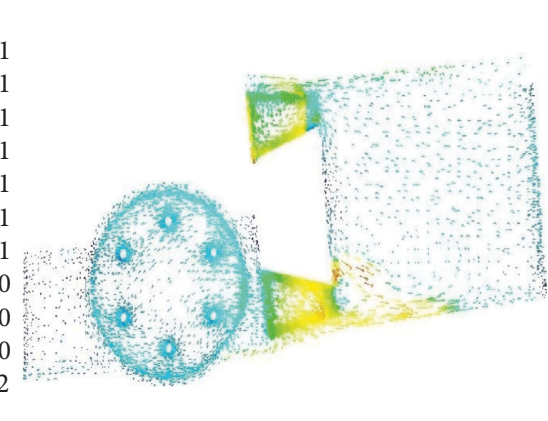

(a)

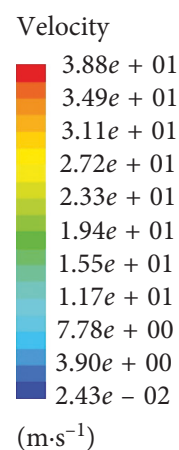

$\left(\mathrm{m} \cdot \mathrm{s}^{-1}\right)$

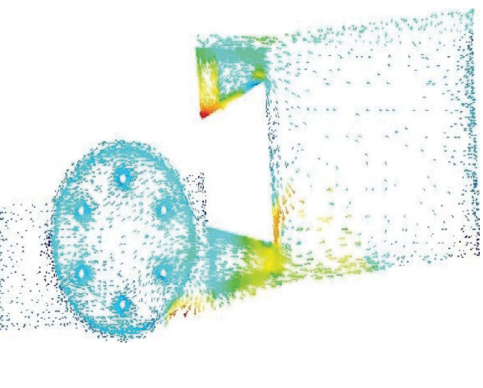

(b)

Figure 6: Overall airflow section characteristics. (a) Two-blade spiral airflow. (b) Three-blade spiral airflow.

The total intake airflow in the boundary area can be obtained by the fluent reporting function. The total intake airflow in the boundary area of two- and three-blade spiral structures is shown in Figure 7.

As shown in Figure 7, the total airflow of the two-blade spiral structure was $1.17 \mathrm{~m}^{3} / \mathrm{s}$. The outlet airflow rate of the entire negative pressure spiral feeding device was $1.04 \mathrm{~m}^{3} / \mathrm{s}$. However, the total airflow of the three-blade spiral structure was $0.97 \mathrm{~m}^{3} / \mathrm{s}$. The outlet flow rate of the entire negative pressure spiral feeding device was $0.86 \mathrm{~m}^{3} / \mathrm{s}$.

The airflow intake and airflow output of the two types of spiral structures were basically the same. However, the internal airflow reflow phenomenon of the three-blade spiral structure was more serious than the interior of the two-blade spiral structure. The air velocity equipotential lines of the two- and three-blade spiral structures are shown in Figure 8.

As shown in Figure 8, the high-speed airflow inlet area of the two-blade spiral structure concentrated on one side of the blade rotation direction. The maximum airflow speed was $11.5 \mathrm{~m} / \mathrm{s}$. It can be seen from the equipotential line that airflow speed on the right side of the entrance was relatively stable. The right airflow speed fluctuations were mainly concentrated on the side walls. The large airflow velocity at the air inlet of the spiral blade was more conducive to the transport of rice straw. The intake velocity of the three-blade spiral structure was high on both sides and low in the middle. In order to ensure the smooth flow of straw at the tangential and longitudinal axial intersection, the effect of two-blade spiral structure was more suitable. Wang et al. simulated the flow field distribution in the axial flow pump device [27]. The blade suction and pressure side pressure distribution under different heads were obtained. The velocity profile of the impeller cylindrical section under different heads was similar to the airflow velocity at the spiral feed head of this paper. It can be seen that there was a certain similarity between the spiral feed head of the longitudinal axial flow threshing drum and the axial flow pump.

3.2. Feed Head Parameters. In the same way, the airflow field analysis of the two-blade spiral structure at different shroud pitches can be obtained. The shroud of the spiral blade had three guiding pitches of $30 \mathrm{~mm}, 40 \mathrm{~mm}$, and $50 \mathrm{~mm}$. The

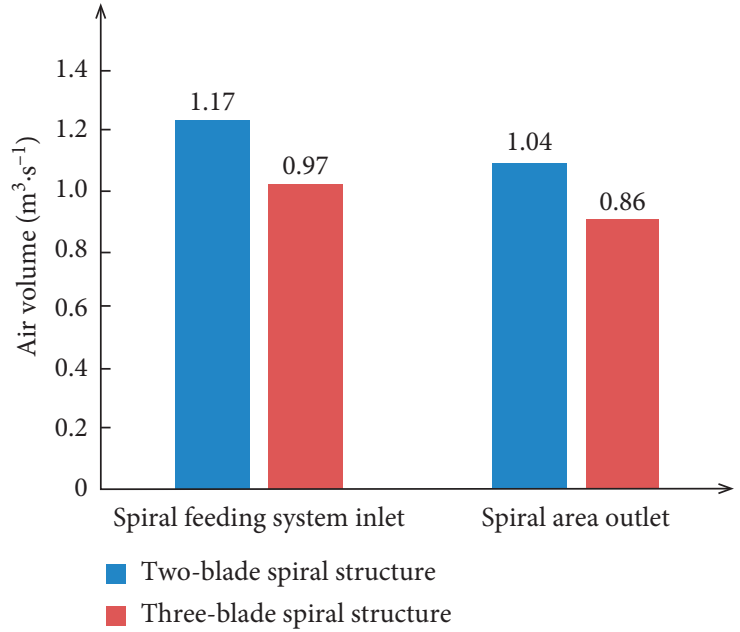

FIgURE 7: Total airflow of two- and three-blade spiral structures at inlet and outlet.

center profile of the spiral feed device was selected for airflow field analysis with different shrouds of the spiral blade. The pitch of the different shrouds had little effect on the internal airflow field of the tangential and longitudinal axial threshing devices. When the pitch of the shroud was $40 \mathrm{~mm}$ and $50 \mathrm{~mm}$, there was a significant airflow reflow phenomenon at the spiral feed head of the longitudinal axial threshing cylinder. However, when the splint pitch was $30 \mathrm{~mm}$, the airflow was smooth. When the pitch of the shroud was $30 \mathrm{~mm}, 40 \mathrm{~mm}$, and $50 \mathrm{~mm}$, the inlet flow velocity of the spiral blade feeding inlet was $2.05-5.50 \mathrm{~m} / \mathrm{s}$, $1.71-4.97 \mathrm{~m} / \mathrm{s}$, and $1.55-4.47 \mathrm{~m} / \mathrm{s}$. Airflow at inlet and outlet with different shroud pitches is shown in Figure 9.

As shown in Figure 9, to avoid backflow problems at the tangential and longitudinal axial intersection, a $30 \mathrm{~mm}$ pitch shroud should be chose. Therefore, in order to make the rice straw more smoothly transported at spiral feeding device, the pitch guide should be $30 \mathrm{~mm}$.

\subsection{Feeding Airflow of Negative Pressure Spiral Feeding} Device. Negative pressure spiral feeding device included shroud front transition plate, external shroud of spiral blade, 


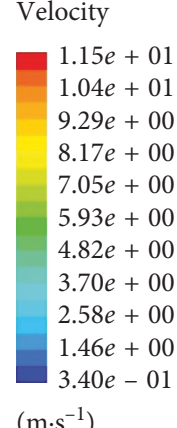
$\left(\mathrm{m} \cdot \mathrm{s}^{-1}\right)$

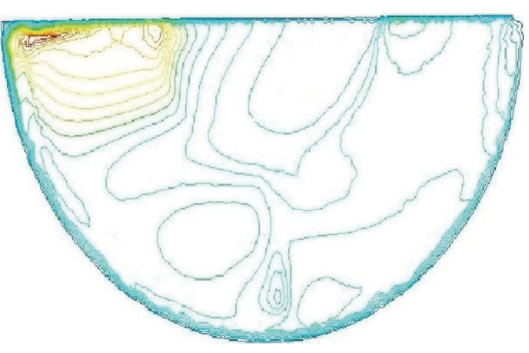

(a)

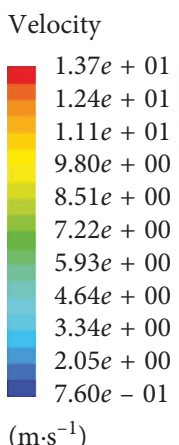

$\left(\mathrm{m} \cdot \mathrm{s}^{-1}\right)$

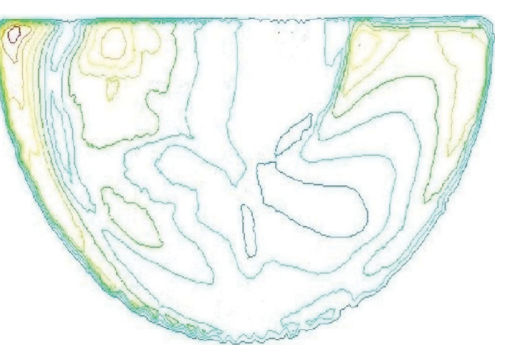

(b)

Figure 8: Airflow velocity equipotential lines at inlet part. (a) Two-blade spiral structure. (b) Three-blade spiral structure.

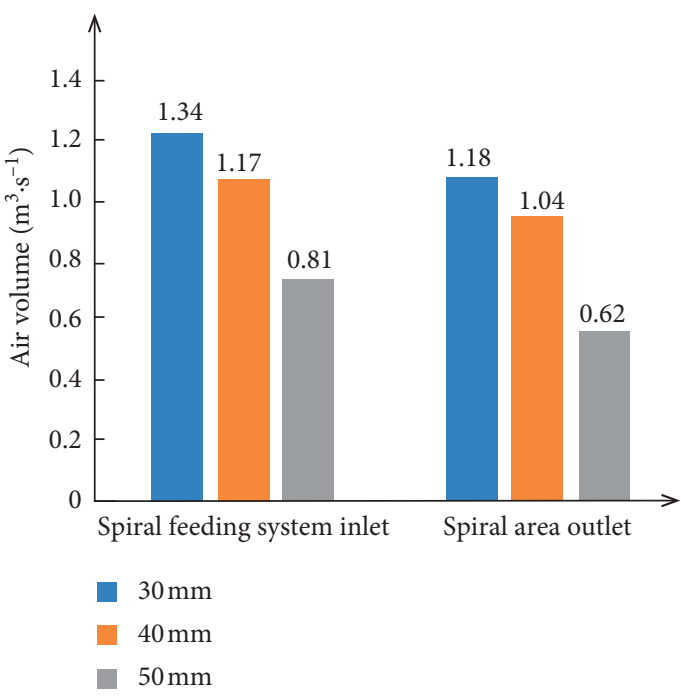

Figure 9: Center profile airflow characteristic at inlet and outlet with different shroud pitches.

and two-blade spiral structure. Based on the CFD simulation and analysis results, when the splint pitch and blade spiral were $30 \mathrm{~mm}$ and two-blade spiral structure, the airflow was smooth. These variables were more suitable for negative pressure spiral feeding device. The test sample of shroud front transition plate, external shroud of spiral blade, and two-blade spiral structure were processed. The results are shown in Figure 10.

In order to test the rationality of the design and processing assembly of the negative pressure spiral feeding device, the airflow velocity measurement results at the spiral feed head are shown in Table 1.

According to the wind speed point distribution map of Figure 4(c), the upper polar coordinate radius position was set to $r(Y)=215 \mathrm{~mm}$, the middle layer was set to $r(Y)=295 \mathrm{~mm}$, and the lower layer was set to $r(Y)=375 \mathrm{~mm}$. Based on the test results of Table 1, airflow velocity distribution polar cloud map was drawn by Origin 9.0. The spiral feed inlet semicircular airflow velocity cloud map is shown in Figure 11.

As shown in Figure 11, at the inlet of spiral feed head, the maximum velocity, the lowest airflow velocity, and the average airflow velocity were $4.59 \mathrm{~m} / \mathrm{s}, 3.76 \mathrm{~m} / \mathrm{s}$, and $4.14 \mathrm{~m} / \mathrm{s}$, respectively. The airflow velocity was larger in the direction of $60^{\circ}$, where the rice straw was caught by the spiral blade. The airflow velocity at the inlet of spiral feeding head was distributed in a layered manner on the half circumference. At the upper wall, the airflow velocity was lower. The lower layer airflow velocity was second. The middle layer airflow velocity was higher.

\subsection{Effectiveness of Negative Pressure Spiral Feeding Device.} The tangential and longitudinal axial intersection was designed by the CFD idea of fluid pump structure. And, the fluid simulation of ANSYS fluent of the tangential and longitudinal axial intersection was executed. The tangential and longitudinal axial intersection structural parameters obtained by ANSYS fluent simulation were processed. The airflow velocity at the entrance of the tangential and longitudinal axial intersection was tested to verify the rationality of the ANSYS fluent simulation design. The performance test of rice feeding was carried out on the tangential and longitudinal axial intersection structures.

In order to compare the power consumption required for structural of unimproved and improved grid gravure spiral feed structure, the power curves of longitudinal axial threshing cylinder were tested at forward speed of $0.98 \mathrm{~m} / \mathrm{s}$ with straw stubble height of $20 \mathrm{~cm}$. Two types of power consumption curves were tested under the same feeding conditions of $7 \mathrm{~kg} / \mathrm{s}$. The power consumption of unimproved grid gravure spiral feed structure and the improved shroud negative pressure spiral feed structure was tested. Power curve of the longitudinal axial threshing cylinder shaft is shown in Figure 12.

Under the same threshing conditions of the longitudinal axial threshing cylinder, the power consumption on the drive shaft of the longitudinal axial threshing cylinder mainly included the power consumption of the spiral feeding head for grasping rice straw and the power consumption of the threshing cylinder. The difference in the power consumption curve shown in Figure 12 was mainly due to the difference in the spiral feeding head for grasping the rice straw. 


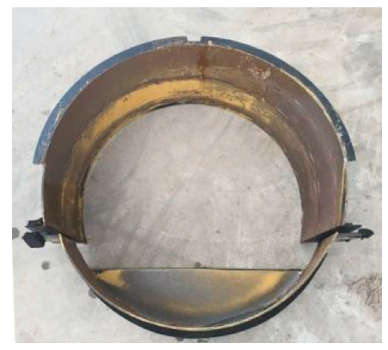

(a)

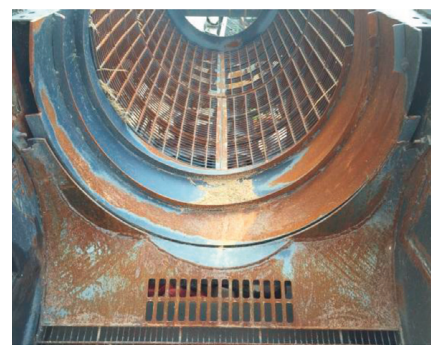

(b)

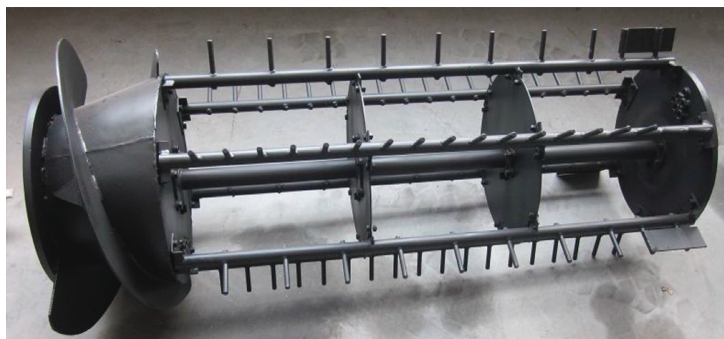

(c)

Figure 10: Negative pressure spiral feeding device. (a) External shroud of spiral blade. (b) Shroud and transition plate assembly. (c) Twoblade spiral of the longitudinal axial threshing cylinder.

TABLE 1: Airflow velocity values within a semicircular cross section $(\mathrm{m} / \mathrm{s})$.

\begin{tabular}{lccccccc}
\hline $\begin{array}{l}\text { Semicircular cross } \\
\text { section }\end{array}$ & 1 & 2 & 3 & 4 & 5 & 6 & 7 \\
\hline 1 (upper layer) & 4.22 & 4.13 & 3.96 & 4.03 & 3.86 & 4.01 & 4.26 \\
2 (middle layer) & 4.29 & 4.53 & 4.59 & 4.13 & 4.38 & 4.58 & 4.43 \\
3 (lower layer) & 4.14 & 3.76 & 3.89 & 3.96 & 4.07 & 3.79 & 4.02 \\
\hline
\end{tabular}

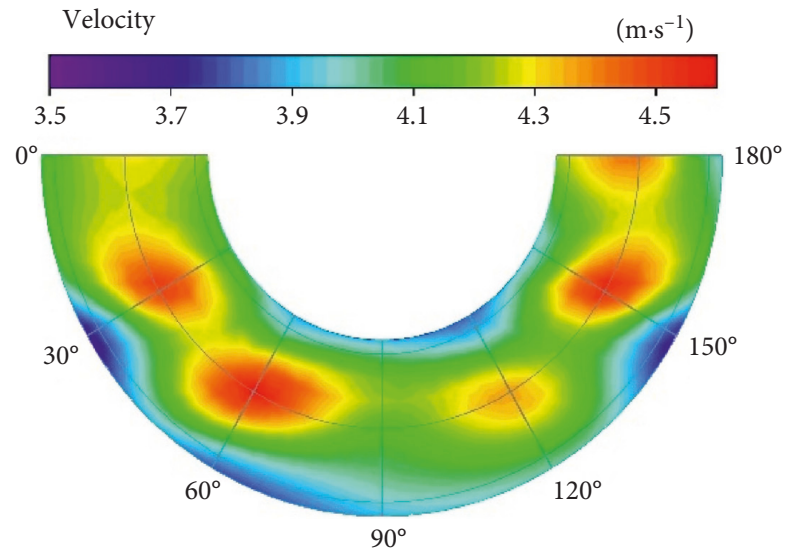

FIGURE 11: Negative pressure spiral feeding airflow velocity cloud map.

As shown in Figure 12(a), the power consumption curve of unimproved grid gravure spiral feed structure was collected within 34 seconds. As shown in the power consumption curve, there was a periodic power consumption fluctuation phenomenon. The fluctuation period of the power consumption curve was $6.5 \mathrm{~s}-7.5 \mathrm{~s}$. The power curve fluctuations in each cycle were similar to the right tilted "W" shape. The power consumption curve had an upward trend in each cycle. The power curve peaked from $50 \mathrm{~kW}$ to $62 \mathrm{~kW}$. The range of power consumption fluctuations had expanded from 40 to $50 \mathrm{~kW}$ to $37-62 \mathrm{~kW}$. The power consumption fluctuation amplitude had increased by about 2.5 times. The upward trend of the power consumption curve and fluctuation amplitude of unimproved grid gravure spiral feed structure were obvious. As shown in Figure 12(b), the power consumption curve of improved shroud spiral feed structure was collected within 36 seconds. As shown in the power consumption curve, the power consumption of negative pressure spiral feeding device was a stable regular fold line. The fluctuation period of the power consumption curve was about $2 \mathrm{~s}$. The range of power consumption fluctuations was $32-52 \mathrm{~kW}$. The power consumption of improved shroud negative pressure spiral feeding device was also lower about $10 \mathrm{~kW}$ than that of the unimproved grid gravure spiral feeding device.

In Tang's doctoral thesis [28], the threshing power consumption during the threshing process was tested and analyzed. When straw trajectory changed from tangential motion to axial motion, straw clogging problem would happen at the tangential and longitudinal axial intersection. The combined device of tangential and longitudinal axial threshing cylinder intersection was unimproved grid gravure spiral feed structure. The straw clogging problem at the tangential and longitudinal axial intersection is shown in Figure 13.

As shown in Figure 13(a), there was a straw clogging problem at the tangential and longitudinal axial intersection. When the spiral feeding device was clogging, the power consumption curve of the barrel sharply increased. Damping and power consumption characteristics during the threshing process are shown in Figure 13(b). The power consumption curve had the characteristic of rising and then falling. When the power consumption curve had an always upward trend, it mean that congestion was about to happen. Changes in the power consumption curve were also often used to be an important sign to determine whether the barrel was clogging.

Figure 12(a) and 13(b) show the same characteristics, which was power consumption curve fluctuated up and down with an upward trend. However, the power consumption curve of improved shroud spiral feed structure was a stable regular fold line without an upward trend. So, the power consumption curve rising and then falling was mainly caused by the resistance of feeding head to feed the rice straw. If the power consumption curve rose too much, it means that the spiral feeding head was clogged. Comparing the power consumption required for structural of unimproved and improved grid gravure spiral feed structure, the characteristics of the power consumption curve indicated that the shroud negative pressure spiral feed device designed in this paper was reasonable and effective.

\section{Conclusions}

(1) The negative pressure spiral feeding device intake airflow velocity of three-blade spiral structure was 


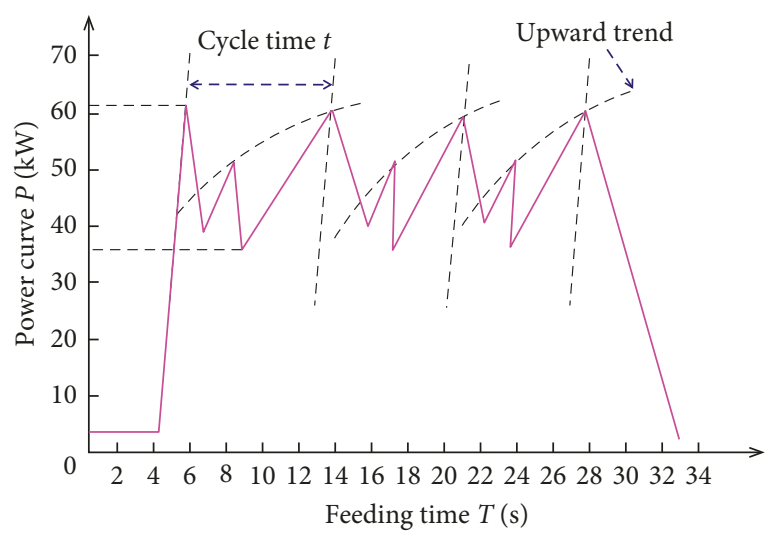

(a)

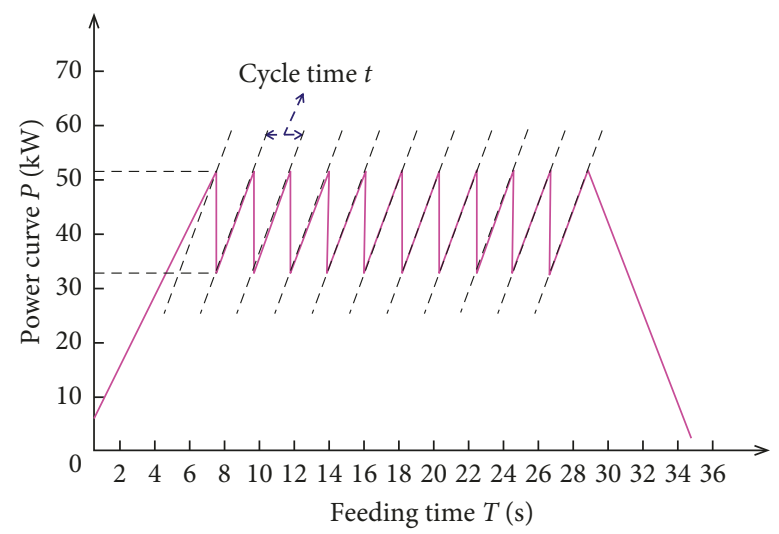

(b)

FIgURe 12: Power curve of the longitudinal axial threshing cylinder shaft. (a) Unimproved grid gravure spiral feed structure. (b) Improved shroud spiral feed structure.

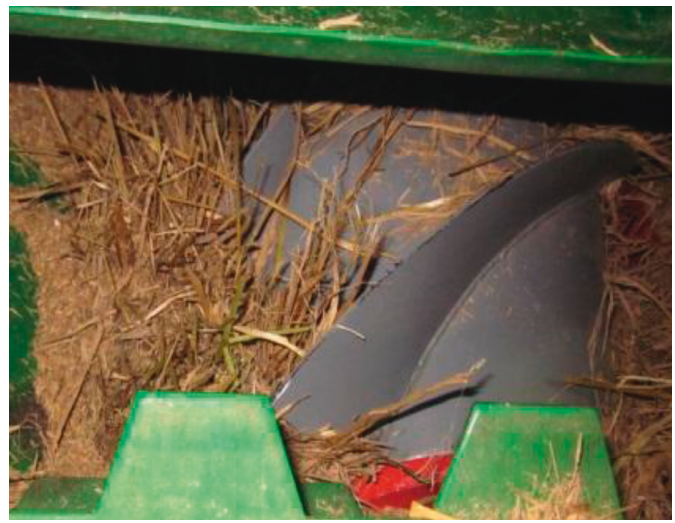

(a)

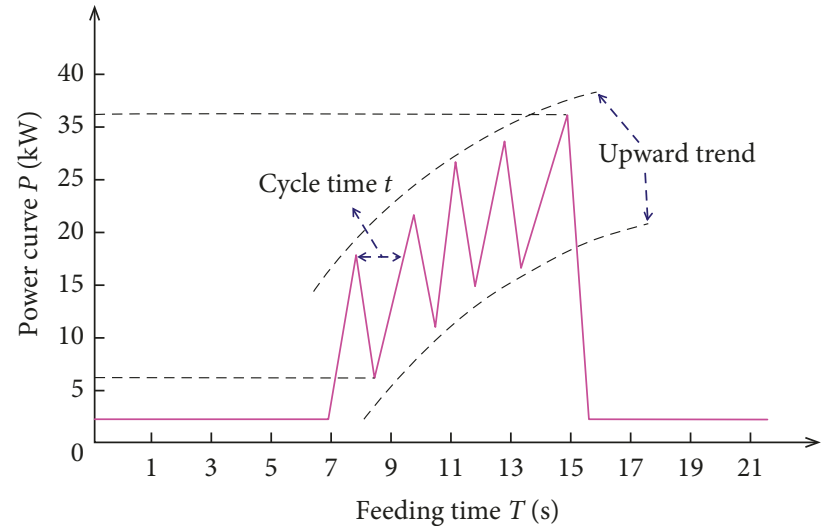

(b)

Figure 13: Straw clogging problem at the tangential and longitudinal axial intersection. (a) Straw blockage status. (b) Power curve at blockage.

high on both sides and low in the middle. The maximum airflow speed $11.5 \mathrm{~m} / \mathrm{s}$ of the twoblade spiral structure concentrated on one side of the blade rotation direction. In order to ensure the smooth flow of straw at the tangential and longitudinal axial intersection, the effect of two-blade spiral structure was more suitable. When the pitch of the shroud was 40 and $50 \mathrm{~mm}$, there was a significant airflow reflow phenomenon at the spiral feed head of the longitudinal axial threshing cylinder. In order to make the rice straw more smoothly transported at spiral feeding device, the pitch guide should be $30 \mathrm{~mm}$.

(2) At the negative pressure spiral feeding device inlet of spiral feed head, the maximum velocity, the lowest airflow velocity, and the average airflow velocity were $4.59 \mathrm{~m} / \mathrm{s}, 3.76 \mathrm{~m} / \mathrm{s}$, and $4.14 \mathrm{~m} / \mathrm{s}$, respectively. At the upper wall, the airflow velocity was lower. The lower layer airflow velocity was second. The middle layer airflow velocity was higher. Power consumption of improved shroud negative pressure spiral feeding device was stable and smooth than that of unimproved grid gravure spiral feeding device.

(3) The power consumption curve of unimproved grid gravure spiral feed structure fluctuated up and down with an upward trend. However, that of improved shroud spiral feed structure was a stable regular fold line without an upward trend. The power consumption curve rising and falling was mainly caused by the resistance of feeding head to feed rice straw. When the power consumption curve had an always upward trend, it means that congestion was about to happen. Changes in the power consumption curve could be an important sign to determine whether the barrel was clogging.

\section{Data Availability}

The data used to support the findings of this study are available from the corresponding author upon request. 


\section{Conflicts of Interest}

The authors declare that they have no conflicts of interest.

\section{Acknowledgments}

This research work was supported by the National Natural Science Foundation of China (51705212), the Natural Science Foundation of Jiangsu Province (BK20170553), the National Key Research and Development Plan (2016YFD0702004), the research proposal of Jiangsu University (17A319), and a project funded by the Priority Academic Program Development of Jiangsu Higher Education Institutions (PAPD).

\section{References}

[1] Z. Tang, Y. M. Li, Z. Zhao, and T. Sun, "Structural and parameter design of transverse multi-cylinders device on rice agronomic characteristics," Spanish Journal of Agricultural Research, vol. 13, no. 4, pp. 1-12, 2015.

[2] Y. M. Li, Z. Tang, L. Z. Xu, Z. Zhao, and H. C. Li, "Power analysis and experimental on longitudial axial-threshing unit test-bed," Transactions of the Chinese Society for Agricultural Machinery, vol. 42, no. 6, pp. 93-97, 2015.

[3] Z. H. Lu, "Power consumption measurement and its calculation on comb-threshing mechanism," Transactions of the Chinese Society for Agricultural Machinery, vol. 1991, no. 2, pp. 34-40, 1991.

[4] W. Srison, S. Chuan-Udom, and K. Saengprachatanarak, "Effects of operating factors for an axial-flow corn shelling unit on losses and power consumption," Agriculture and Natural Resources, vol. 50, no. 5, pp. 421-425, 2016.

[5] N. Mazara, A. J. Hess, J. Chen, and G. A. Power, "Activation reduction following an eccentric contraction impairs torque steadiness in the isometric steady-state," Journal of Sport and Health Science, vol. 7, no. 3, pp. 310-317, 2018.

[6] T. Michele, M. Francesco, and C. Claudio, "Comparative evaluation of insertion torque and mechanical stability for self-tapping and self-drilling orthodontic miniscrews-an in vitro study," Head and Face Medicine, vol. 13, no. 1, pp. 1-10, 2017.

[7] Y. N. Li, J. S. Chen, Q. S. Ding, and W. M. Ding, "Effects of axial flow and tangential flow mechanical threshing on rice damage and milling quality," Transactions of the Chinese Society of Agricultural Engineering, vol. 33, no. 15, pp. 41-48, 2017.

[8] C. C. Wei, Y. M. Li, L. Z. Xu, Z. W. Liang, and J. P. Wang, "Design and experimental study of large feed quantity crawler full feeding rice combine harvester," Agricultural Mechanization Research, vol. 8, pp. 70-75, 2018.

[9] Z. Qu, D. X. Zhang, L. Yang, T. L. Zhang, Z. D. Wang, and T. Cui, "Experiment on feed rate and cylinder speed of longitudinal axial flow threshing and separating device for maize," Transactions of the Chinese Society for Agricultural Machinery, vol. 49, no. 2, pp. 58-65, 2018.

[10] Y. Su, H. Liu, Y. Xu, T. Cui, Z. Qu, and D. X. Zhang, "Optimization and experiment of spike-tooth elements of axial flow corn threshing device," Transactions of the Chinese Society for Agricultural Machinery, vol. 49, pp. 258265,2018

[11] X. F. Wu, Y. D. Lu, M. G. Tan, and H. L. Liu, "Effect of vane angle on axial flow pump running characteristics in saddle zone," Transactions of the Chinese Society of Agricultural Engineering, vol. 34, no. 17, pp. 46-53, 2018.

[12] N. C. He, M. G. Tan, H. L. Liu, X. Huang, and X. F. Wu, "Test and analysis on pressure pulsation and hydraulic performance of saddle zone in axial flow pump," Journal of Drainage and Irrigation Machinery Engineering, vol. 36, no. 2, pp. 118-123, 2018.

[13] M. Q. Wang, Y. J. Li, S. Q. Yuan, and F. Meng, "Runaway characteristics of two-way passage axial-flow pump installation," Journal of Drainage and Irrigation Machinery Engineering, vol. 36, no. 5, pp. 384-390, 2018.

[14] Y. L. Wu, J. Liu, and T. J. Chen, Design and Example of Vane Pump, China Machine Press, Beijing, China, 2011.

[15] X. Mao and S. J. Yi, "Motion research on grain fluid at planktooth of assembled axial-flow device," Machinery Design and Manufacture, vol. 2011, no. 7, pp. 75-78, 2011.

[16] Z. Tang, Y. Li, L. Xu, and F. Kumi, "Modeling and design of a combined transverse and axial flow threshing unit for rice harvesters," Spanish Journal of Agricultural Research, vol. 12, no. 4, pp. 973-983, 2014.

[17] F. Yang, C. Liu, and F. P. Tang, "Numerical analysis and prediction of hydraulic performance for axial-flow pumping system with adjustable outlet guide vanes," Transactions of the Chinese Society of Agricultural Machinery, vol. 46, no. 4, pp. 40-46, 2015.

[18] H. T. Li, X. Y. Wan, H. Wang, Y. J. Jiang, and Q. X. Liao, "Design and experiment on integrated longitudinal axial flow threshing and separating device of rape combine harvester," Transactions of the Chinese Society of Agricultural Engineering, vol. 48, no. 5, pp. 108-116, 2017.

[19] Y. Chen, "Parameters optimization and tests of threshing and separation device in oblique tangential-longitudinal combine," Master thesis, Jiangsu Univesity, Zhenjiang, China, 2016.

[20] X. Luo, Y. Zhen, and J. Feng, "Hydraulic performance analysis of axial pump outlet guide vane," Water Resources and Power, vol. 32, no. 3, pp. 188-191, 2014.

[21] F. J. Wang, Computational Fluid Dynamics Analysis-Principle and Application of CFD Software, Tsinghua University Press, Beijing, China, 2004.

[22] J. B. Krolczyk, S. Legutko, and G. M. Krolczyk, "Dynamic balancing of the threshing drum in combine harvesters-the process, sources of imbalance and negative impact of mechanical vibrations," Applied Mechanics and Materials, vol. 693, no. 3, pp. 424-429, 2014.

[23] S. Koynov, Y. Wang, A. Redere et al., "Measurement of the axial dispersion coefficient of powders in a rotating cylinder: dependence on bulk flow properties," Powder Technology, vol. 292, no. 5, pp. 298-306, 2016.

[24] R. C. Zhang and Z. Z. Sang, "Research on the power consumption model of axial threshing cylinder," Transactions of the Chinese Society for Agricultural Machinery, vol. 15, no. 4, pp. 121-125, 1999.

[25] Y. P. Guo and T. M. Wang, "Stabilization of a nonhomogeneous rotating body-beam system with the torque and nonlinear distributed controls," Journal of Systems Science and Complexity, vol. 30, no. 3, pp. 626-634, 2017.

[26] Z. Tang, Y. M. Li, and J. B. Liu, "Dynamic vibration test and analysis of $4 \mathrm{LZ}-2.5 \mathrm{~B}$ combine harvester cutting table rack in wheat harvesting," International Agricultural Engineering Journal, vol. 26, no. 1, pp. 79-86, 2017.

[27] D. X. Wang, W. D. Cao, Y. L. Zhang, X. J. Liu, and J. X. Ma, "Effects of volute cross-section shape and impeller position on volute type axial flow pump performance," Journal of 
Drainage and Irrigation Machinery Engineering, vol. 34, no. 2, pp. 105-109, 2018.

[28] Z. Tang, Theoretical and experimental investigations of cereals threshing and separation on tangential- longitudinal axial device, Ph.D. thesis, Jiangsu University, Zhenjiang, China, 2015. 


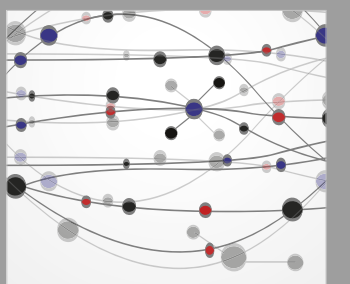

The Scientific World Journal
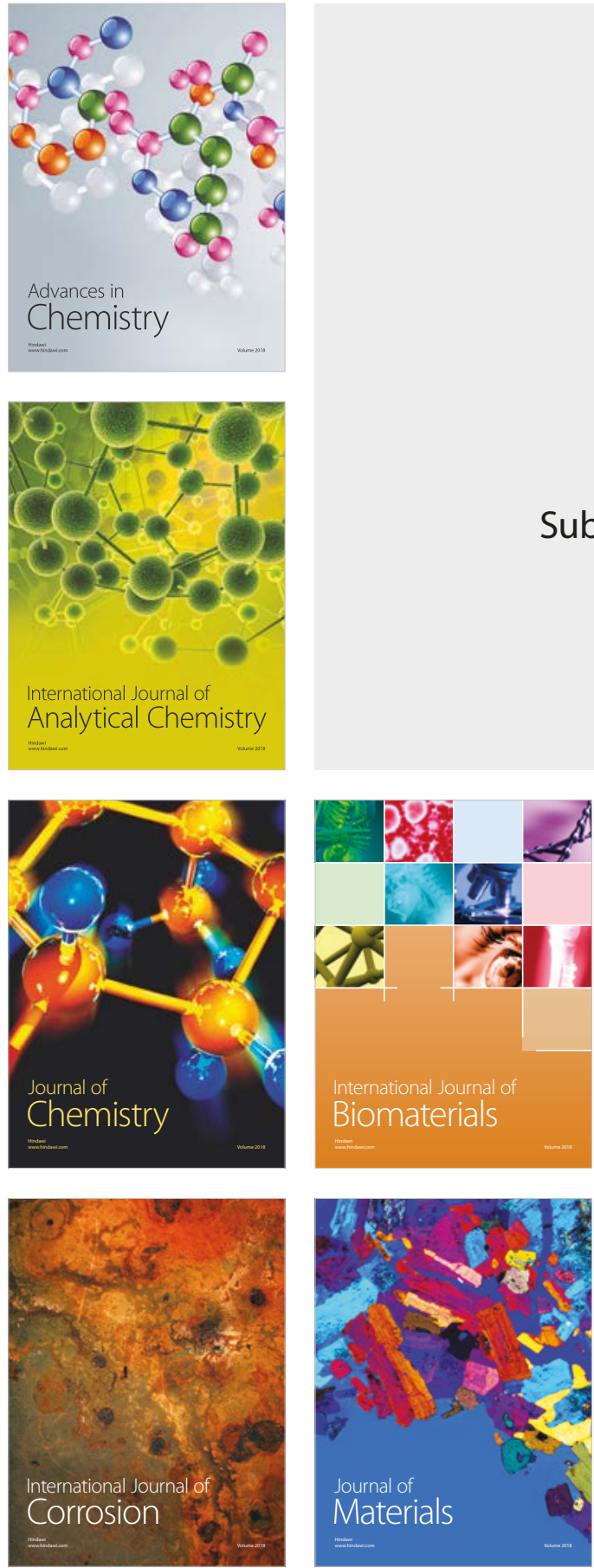

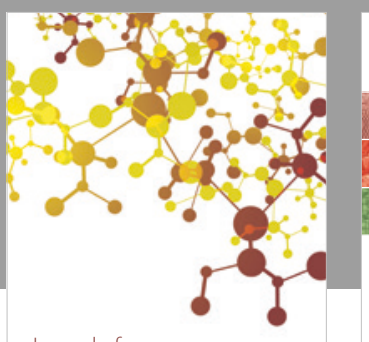

Journal of

Applied Chemistry
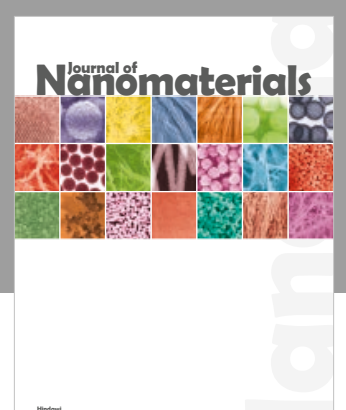

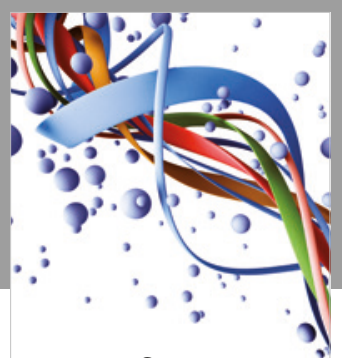

Scientifica

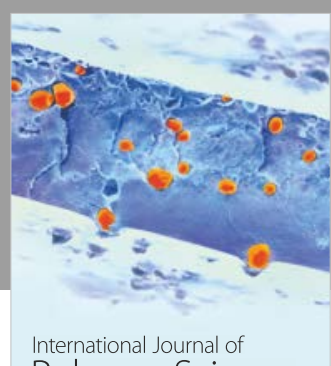

Polymer Science

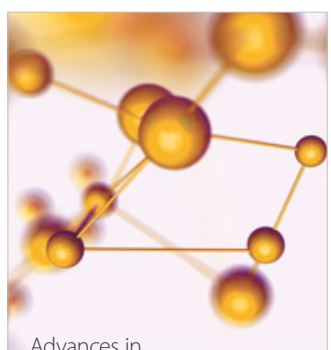

Physical Chemistry
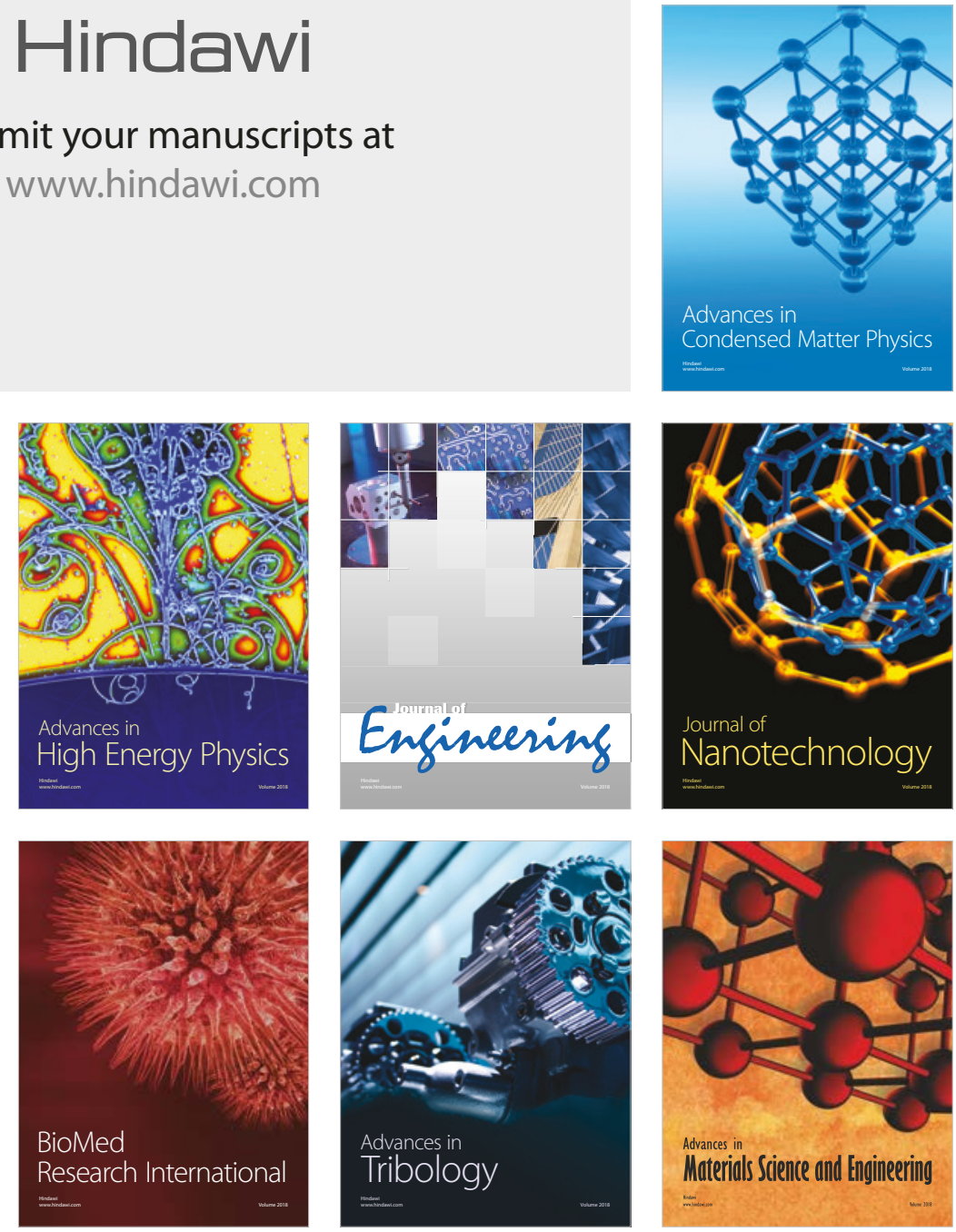